\title{
Prevalence of Sexual Dysfunction and Related Risk Factors in Men with Multiple Sclerosis in Iran: A Multicenter Study
}

\author{
Seyed Massood Nabavi · Maryam Dastoorpoor • Nastaran Majdinasab • \\ Narges Khodadadi (D) - Narges Khanjani · Zohreh Sekhavatpour • \\ Maryam Zamanian · Sasan Kazemian · Amir Ebrahim Eftekhari • \\ Fereshteh Ashtari · Roya Abolfazli • Mahdi Jalili • Gholamhossein Ghaedi • \\ Hamid Reza Ghalianchi \\ Received: January 28, 2021 / Accepted: May 5, 2021 / Published online: May 18, 2021 \\ (C) The Author(s) 2021
}

\section{ABSTRACT}

Introduction: Sexual dysfunction (SD) is a common complaint in patients with multiple sclerosis (MS). The aim of this study was to

S. M. Nabavi · S. Kazemian · A. E. Eftekhari Department of Regenerative Biomedicine, Royan Institute for Stem Cell Biology and Technology, ACCR, Tehran, Iran

\section{S. M. Nabavi}

Department of Brain and Cognition, Royan Institute for Stem Cell Biology and Technology, ACCR, Tehran, Iran

\section{Dastoorpoor $(\bowtie) \cdot$ N. Khodadadi}

Department of Biostatistics and Epidemiology, Social Determinants of Health Research Center, Ahvaz Jundishapur University of Medical Sciences, Ahvaz, Iran

e-mail: mdastoorpour@yahoo.com;

dastoorpoor-m@ajums.ac.ir

\section{N. Majdinasab}

Department of Neurology, School of Medicine, Musculoskeletal Rehabilitation Research Center, Golestan Hospital, Ahvaz Jundishapur University of Medical Sciences, Ahvaz, Iran

\section{N. Khanjani}

Neurology Research Center, Shafa Hospital, Kerman University of Medical Sciences, Kerman, Iran

\section{Z. Sekhavatpour}

Department of Anesthesiology, School of Allied Medical Sciences, Dezful University of Medical Sciences, Dezful, Iran assess the prevalence of SD and its related risk factors in men with MS in Iran.

Methods: In this cross-sectional study, 320 men who had been diagnosed with MS according to the McDonald revised criteria were recruited from January to June 2019, from the north, south, east,

\section{Zamanian}

Department of Health, School of Health, Arak University of Medical Sciences, Arak, Iran

\section{F. Ashtari}

Department of Neurology, School of Medicine, Neurosciences Research Center, Isfahan University of Medical Sciences, Isfahan, Iran

\section{R. Abolfazli}

Department of Neurology, School of Medicine, Tehran University of Medical Sciences, Tehran, Iran

M. Jalili

Schools of Medicine, Dezful University of Medical Sciences, Dezful, Iran

G. Ghaedi

School of Medicine, Neurophysiology Research

Center, Shahed University, Tehran, Iran

H. R. Ghalianchi

Ghaem Medical Center, Rasht, Iran 
west, and central parts of Iran. Patients were assessed using the Male Sexual Health Questionnaire (MSHQ), International Index of Erectile Function (IIEF), The Multiple Sclerosis Intimacy and Sexuality Questionnaire-(MSISQ 19), Sexual Quality of Life-Men (SQOL-M), and Standard General Health Questionnaire (GHQ).

Results: Sexual dysfunction, defined as total IIEF score $\leq 45$ was present in 114 patients $(35.6 \%)$. The results of univariate logistic regression showed that there were significant direct relations between age (OR 1.050, 95\% CI 1.02-1.08), Expanded Disability Status Scale (EDSS) (OR 1.45, 95\% CI 1.24-1.7), duration of MS (OR 1.005, 95\% CI 1.002-1.009), MSISQ-19 (OR 1.103, 95\% CI 1.078-1.128), GHQ (OR 1.04, 95\% CI 1.03-1.06), SQOL-M (OR 0.930, 95\% CI 0.914-0.947), smoking (OR 1.941, 95\% CI 1.181-3.188), non-MS chronic disease (OR 1.91, $95 \%$ CI $1.20-3.04$ ), having a main sexual partner (OR 2.56, 95\% CI 1.32-4.94), and significant inverse relations between exercise (OR 0.584, 95\% CI 0.364-0.936) and regular sexual activity (OR 0.241, 95\% CI 0.15-0.40), with the prevalence of SD. The results of multiple logistic regression indicated that the age, MSISQ-19, and SQOL-M were the only independent predictive factors for SD in these patients.

Conclusion: The prevalence of SD in men with MS in Iran is relatively high. These patients should be screened, diagnosed, and treated for SD and influencing factors.

Keywords: Men; Multiple sclerosis; Sexual dysfunction

\section{Key Summary Points}

\section{Why carry out this study?}

Sexual dysfunction is very common in patients with multiple sclerosis and imposes a significant burden, while as a result of cultural issues it often remains unknown.

The present study investigated the prevalence and factors related to sexual dysfunction in men with multiple sclerosis in Iran.

\section{What was learned from the study?}

The prevalence of sexual dysfunction in men with multiple sclerosis was 36\%.

While factors including age, depression, smoking, other chronic diseases, and having a main sexual partner had a positive association with chance of sexual dysfunction, exercise and regular sexual activity had a negative association with sexual dysfunction.

It is necessary to inform patients that sexual dysfunction is a common problem in multiple sclerosis and they should talk about their sexual concerns.

\section{DIGITAL FEATURES}

This article is published with digital features, including a summary slide, to facilitate understanding of the article. To view digital features for this article go to https://doi.org/10.6084/ m9.figshare. 14540721 .

\section{INTRODUCTION}

Multiple sclerosis (MS) is a chronic central nervous system disease that causes paralysis, and sensory and balance system disorders, by destroying the myelin sheath of neural cells [1]. In most cases, symptoms appear between the ages of 20 and 40 . The average global prevalence of this disease has risen from 10 per 100,000 in 2008 to 33 per 100,000 in 2013 [2]. The prevalence of this disease in Iran has also increased dramatically in the last 20 years [3, 4]. Tehran province is a high risk area with the prevalence of 70 per 100,000 people [5], and the incidence is higher among women [4]. The disease process is unpredictable. Usually, the disease starts slowly without periodic attacks, but then it progresses steadily as the symptoms worsen. In some people, the onset of the disease is a relapsing-remitting process, then the disability 
continues to progress by imposing persistent symptoms and without a remission period. The relapsing-remitting type is the most common form of the disease and $80-85 \%$ of patients suffer from this type of MS [5]. Geographical and seasonal factors are important determinants in the distribution of MS. Colder countries have a higher prevalence of MS [5] and some studies have reported higher attack rates in specific seasons [6].

According to the World Health Organization (WHO) definition, sexual dysfunction (SD) is a syndrome that includes absence or loss of libido, sexual anxiety and sexual enjoyment, failure of genital response [erectile dysfunction (ED) in men, vaginal dryness or reduction and absence of vaginal lubricating secretions in women], orgasm disorder, premature ejaculation, vaginismus, and dyspareunia [7]. SD is very common in patients with MS and imposes a significant burden on patients. However, SD often stays unknown in patients with MS, and most patients and physicians are reluctant to discuss it. A review of studies shows that people suffering from MS experience high levels of SD and in most cases are dissatisfied with their sexual relations [8]. But, as a result of cultural issues or dilemmas, patients may be embarrassed to talk about their sexual issues and many doctors do not address this issue, which leads to the lack of diagnosis of sexual disorders in these patients [9]. Studies have shown that between $50 \%$ and $90 \%$ of men with MS suffer from SD [10] and $86 \%$ of men feel that MS has affected the quality of their sex life [11]. Other studies have shown that men complain of SD between 2 and 5 years after being diagnosed with MS [12]. Although SD is not life-threatening, it cannot be ignored either, because it affects quality of life, fertility, and family planning [13]. SD in men with MS is classified as primary, secondary, or tertiary. Primary symptoms include erectile dysfunction, ejaculation disorders, orgasm disorders, and decreased libido, which have been reported in most studies. Secondary symptoms include dysfunction of the bladder and lower limb. The prevalence of secondary symptoms of SD is more difficult to estimate than primary symptoms [14]. Tertiary symptoms refer to the emotional, social, and cultural aspects of the disease that can affect personal sexual activity $[15,16]$.

Foley et al. provided a conceptual model for describing sexual symptoms in patients with MS. Primary SD is caused by neurological changes that directly affect sexual feelings and emotions, resulting in men experiencing SD, decreased libido, inability to obtain or maintain erection, and reduced number of or ability to achieve ejaculation. Second-degree SD is caused by physical changes or the symptoms of disease that indirectly affect sexual responses, which can include fatigue, stiffness, muscle weakness or spasm, bladder and bowel disorders, incoordination, walking difficulty, tremor, cognitive disorders, pain anesthesia, burning or discomfort in non-sexual areas of the body. Third-degree SD refers to a variety of aspects that can affect a person's sexual activity in different ways, such as mood swings, feeling dependent, difficulty in communication with the sexual partner, decreased self-esteem, and depression $[15,16]$.

Depression is an important cause of SD and is associated with MS [17]. Finkelsztejn et al. [18] showed that there is a direct relation between depression and SD in patients with MS. Likewise, in a cross-sectional study, Marck et al. [19] found that SD in patients with MS was related to depression, fatigue, lifestyle, diet, and physical activity.

Another key issue in the sexual health of patients with MS is sexual quality of life. Sexual quality of life refers to sexual attraction, interest and participation in sexual activity, and perception of sexual function [20]. Studies have shown that one of the most important factors in marital life satisfaction and good quality of life is pleasurable sexual relations [21, 22]. Balsamo et al. [23] showed that SD such as erectile dysfunction was directly related to sexual quality of life, age, disability, depression, prostate disorders, and cardiovascular failure in patients with MS in Italy.

The knowledge of health personnel about the prevalence of SD and its related factors can help introduce interventions, new treatments, and proper counseling to these patients. However, despite the importance of diagnosing sexual health problems in men with MS, it 
seems that so far no study has been done to determine the prevalence of these disorders in men with MS in Iran. Therefore, the present study aimed to determine the prevalence of SD and the factors affecting it in men with MS, in a multicenter study.

\section{METHODS}

\section{Participants and Sampling}

This cross-sectional study was conducted in multiple centers in Iran in 2019. The study population consisted of men with MS whose disease was confirmed by a neurologist according to the McDonald's diagnostic criteria. Participants were 320 men selected by cluster random sampling from the MS Registration Centers in six major cities of Iran, namely Tehran, Gilan (north), Isfahan (central Iran), Kerman (east), Ahvaz (southwest), and Dezful (west).

Ethics approval was obtained from the ethics committee of Ahvaz Jundishapur University of Medical Sciences (IR.AJUMS.REC.1399.556). According to the ethics in research regulations in Iran, ethics committee approval was not needed to be obtained from each study site, separately, and the research could proceed with ethics approval from just one Iranian university. This study was performed in accordance with the Helsinki 1964 Declaration. Oral informed consent for participating in this study was obtained from all patients. Personal information was kept confidential.

The sample size was determined according to the study conducted by Previnaire et al. [24], in which the prevalence of SD in men with MS was reported to be between 50\% and 90\%.Assuming a prevalence of $70 \%$ (the mean of $50 \%$ and $90 \%)$, a confidence interval of $95 \%$, and acceptable error of 0.05 , the final sample size was estimated to be 323 patients. The sample size in each city was proportionate to that city's population.

$$
n=\frac{Z^{2} p(1-p)}{d^{2}}=\frac{(1 / 96)^{2} \times 0.7 * 0.3}{0.05^{2}}=323
$$

In this equation, $Z$ is the $z$-score for type I error $(\alpha=0.05)$. $d$ is the acceptable error and $p$ is the prevalence.

\section{Inclusion and Exclusion Criteria}

The inclusion criteria included being diagnosed with MS by a neurologist, personal consent to participate in the study, and ability to understand the content and answer the questions. The exclusion criteria included having a condition that prevents the person from cooperating; and not consenting to participate.

\section{Data Gathering Tools}

Data collection was done in two parts. First of patients were asked about all clinical information by a physician according to a checklist that included duration of MS disease (in months), Expanded Disability Status Scale Score (EDSS), type of disease [secondary progressive MS (SPMS), primary progressive MS (PPMS), progressive-relapsing multiple sclerosis (PRMS), relapsing-remitting MS (RRMS)], type of medicine used for MS treatment [teriflunomide, dimethyl fumarate, Tysabri, fingolimod, rituximab, glatiramer acetate (GA), interferon- $\beta$, taking medication for erection problems, type of medicine used for treating sexual function including SSRI (selective serotonin reuptake inhibitor), composed of fluoxetine, citalopram, and sertraline, Cialis (Tadagra), sildenafil (Viagra), duration of SD (in months), and taking medication to achieve erection in the past month. The second part was a demographic information questionnaire and sexual health questionnaires that were completed by the patient and are listed below.

1. Demographic information questionnaire Included age, marital status, education, spouse's education, number of children, economic status, exercise status, smoking, alcohol consumption, drug use, current chronic illnesses other than MS, history of 
psychological illness, having regular sexual activity, and having a main sexual partner.

2. Male Sexual Health Questionnaire (MSHQ) This questionnaire was designed in 2004 by Rosen et al. [25] to assess the dimensions related to sexual function and satisfaction in men, especially in terms of ejaculatory function. This questionnaire consists of 25 questions in three main dimensions of erection (questions 1-3; score range 0-15), ejaculation (questions 5-11; score range 1-35), and satisfaction (questions 13-18; score range 6-30). There are also additional items related to sexual activity, desire, and bother associated with SD. Each item is scored from zero or one to five. Higher scores indicate better sexual function. Cultural adaptation and validation of the Iranian version of this questionnaire was done by Fakhri et al. [26].

3. International Index of Erectile Function (IIEF) This questionnaire was designed in 1997 by Rosen et al., to assess male erectile dysfunction. It includes 15 questions in five dimensions, namely erectile function, orgasmic function, libido, sexual contact satisfaction, and comprehensive satisfaction [27]. The items have a response range of zero or one to five, with higher scores indicating better sexual function. The score of overall sexual function ranges from 5 to 75 . Cultural adaptation and validation of the Iranian version was done by Fakhri et al. [26]. In this study, IIEF was used to determine the prevalence of SD among the participants. If the total IIEF score was 45 or less, it was considered as SD [27].

4. Multiple Sclerosis Intimacy and Sexuality Questionnaire (MSISQ 19) This questionnaire was designed in 2000 by Sanders et al., to assess primary, secondary, and tertiary SD in patients with MS. The Intimacy and Sexual Activity Questionnaire in patients with MS consists of 19 questions that ask how much the symptoms of MS, in the past 6 months, have prevented sexual activity or satisfaction. Scores are on a Likert scale and include 1 , never; 2 , often; 3 , sometimes; 4 , most of the time; and 5, always. These questions assess the effect of symptoms on patients' sexual activity and satisfaction based on their perceptions. Five of these questions are related to the dimension of primary sexual disorders, nine questions are related to the dimension of secondary sexual disorders, and five questions are related to the dimension of tertiary sexual disorders. The minimum score of this questionnaire is 19 and the maximum is 95. A higher score indicates more SD [15]. This questionnaire was validated and assessed for reliability by Mohammadi et al. [28] in Iran.

5. Sexual Quality of Life-Men (SQOL-M) This questionnaire was designed by Abraham et al. in 2008, to assess sexual quality of life in men. This questionnaire consists of 11 questions on a Likert scale of 6 points from completely agree (score 1) to completely disagree (score 6) with a score range of 11-66. A higher score indicates a better quality of life [29]. This questionnaire was validated by Sadat et al. [30] in Iran.

In this study all four sexual health questionnaires were used in order to have a comprehensive view of the health situation of these patients.

6. Standard General Health Questionnaire (GHQ) In order to assess the mental health status of patients, the 28-item Goldberg and Hillier General Health Questionnaire was used as a screening tool for psychiatric disorders. This 28-item questionnaire consists of four subtests, each with seven questions. Questions 1-7 are related to the subtest of physical symptoms, questions 8-14 are related to the subtest of anxiety and insomnia, questions 15-21 are related to the subtest of social dysfunction, and questions 22-28 are related to the subtest of depression. The questions are asked on a 4-point Likert scale $(0,1,2,3)$, and the total score is between 0 and 84 [31]. This questionnaire was validated by Nourbala et al. [32] in Iran.

\section{Statistical Analysis}

Data were coded and entered into Statistical Package for the Social Sciences (SPSS) software version 20 , and were summarized by descriptive 
statistics. Univariate and multiple logistic regression models, with 95\% confidence intervals were used for statistical analysis. The significance level was considered less than 0.05.

\section{RESULTS}

The mean age of patients was 38.4 years with a range of 17-72 years. The mean EDSS score was $2.6 \pm 1.6$, the mean duration of MS disease was $88.1 \pm 67.6$ months, and the mean duration of SD was $42.3 \pm 46.3$ months. Regarding the type of MS, the majority of patients $(58.8 \%)$ had relapsing-remitting MS. The majority of patients were married $(80.9 \%)$, had children $(89.8 \%)$, a university degree $(57.5 \%)$, and an average economic level (52.8\%); $43.4 \%$ exercised, $28.8 \%$ smoked, and $12.8 \%$ consumed alcohol; $7.2 \%$ had a psychiatric illness and $48.4 \%$ had at least one chronic illness including cardiovascular disease, cancer, diabetes, kidney disease, spinal cord injury, depression, and others; $47.8 \%$ had regular sexual activity and $80.0 \%$ had a main sexual partner; $31.3 \%$ were taking sexual medication and $31.8 \%$ had been taking medicine to get an erection in the past month. According to the IIEF questionnaire, $35.6 \%$ had SD. Other patient details are shown in Table 1.

As Table 2 shows the mean scores of MSISQ19 were $10.4 \pm 5.0$, GHQ $26.4 \pm 13.7$, IIEF $48.0 \pm 11.34$, and SQOL-M $47.9 \pm 16.8$. In the three main subscales of MSHQ, the subscale of erection and ejaculation, respectively, received the lowest $(10.2 \pm 3.8)$ and highest $(26.7 \pm 7.3)$ mean scores.

As Table 3 shows there were direct and significant correlations between SQOL-M and MSHQ and IIEF, and significant inverse correlations between SQOL-M and MSISQ-19 and GHQ.

Table 4 shows the factors associated with SD in men with MS. The results of univariate logistic regression showed that there was a significant relation between age, EDSS, duration of MS, MSISQ-19, GHQ, and SQOL-M scores, exercise, smoking, non-MS chronic disease, regular sexual activity, and having a main sexual partner with the prevalence of SD. As with
Table 1 Summary of demographic and clinical variables in the patients with MS under study

$N(\%)$

Age

Mean \pm standard deviation $38.4 \pm 9.5$

Median, IQR

37,12

EDSS

Mean \pm standard deviation

$2.6 \pm 1.6$

Median, IQR

$3,1.5$

Duration of MS disease (months)

Mean \pm standard deviation

$88.1 \pm 67.6$

Median, IQR

84,84

Duration of sexual dysfunction (months)

Mean \pm standard deviation

$42.3 \pm 46.3$

Median, IQR

24, 48

Age groups

17-39 years

$191(59.7)$

40-49 years

84 (26.3)

$>49$ years

$45(14.1)$

Marital status

Single/separated/widowed

Married

Children

None

One or more

$194(89.8)$

Education

High school or below

$136(42.5)$

University

Spouse education

High school or below

University

$146(56.4)$

Economic status

Good and excellent

$67(20.9)$

Moderate

$169(52.8)$

Weak

84 (26.3) 
Table 1 continued

$N(\%)$

Exercise

Yes
No
Smoking
Yes
No
Alcohol consumption
Yes
No

Drug use

$$
\text { Yes }
$$$$
30(9.4)
$$

No

$290(90.6)$

Any psychiatric illness

$$
\begin{aligned}
& \text { Yes } \\
& \text { No }
\end{aligned}
$$

Non-MS chronic disease

Yes

No

Type of MS

\section{RRMS}

$188(58.8)$

PRMS

PPMS

$14(4.4)$

SPMS

Level of disability

$$
\text { Low }
$$

Moderate

Severe

Regular sexual activity

$$
\text { Yes }
$$

No

Main sexual partner Yes
Table 1 continued

\begin{tabular}{lc}
\hline & $\boldsymbol{N}(\%)$ \\
\hline No & $64(20.0)$ \\
Type of medicine & $150(46.9)$ \\
High efficacy (rituximab, Tysabri) & $170(53.1)$ \\
Low to moderate efficacy (interferon, \\
glatiramer acetate, fingolimod, dimethyl \\
fumarate, teriflunomide) \\
$\begin{array}{l}\text { Taking medicine to achieve an erection in the past month } \\
\text { Yes }\end{array}$ \\
No & $44(13.8)$ \\
\end{tabular}

Taking sexual medicine

Yes

$100(31.3)$

No

Type of sexual medicine

SSRI

$67(67.0)$

Cialis

Sildenafil

Prevalence of sexual dysfunction according to the IIEF questionnaire

Yes $114(35.6)$

No $206(64.4)$

SSRI selective serotonin reuptake inhibitor, IQR interquartile range, $R R M S$ relapsing-remitting multiple sclerosis, SPMS secondary progressive multiple sclerosis, PPMS primary progressive multiple sclerosis, RPMS relapsing-progressive multiple sclerosis, IIEF International Index of Erectile Function, EDSS Expanded Disability Status Scale

increasing age, the EDSS, MSISQ-19, and GHQ score, and the duration of MS, the chances of having SD increased; and with increasing SQOL$M$ score, the chances of having SD decreased. Exercise and regular sexual activity were inversely related to SD. Smoking and chronic diseases such as diabetes, hypertension, and cardiovascular diseases increased the chance of having SD. 
Table 2 Mean of MSISQ-19, MSHQ, GHQ, IIEF, and SQOL-M in patients participating in this study $(n=320)$

\begin{tabular}{|c|c|c|c|c|c|}
\hline Variable & Class & Mean & $\begin{array}{l}\text { Standard } \\
\text { deviation }\end{array}$ & Min & $\operatorname{Max}$ \\
\hline \multirow[t]{4}{*}{$\begin{array}{c}\text { MSISQ- } \\
19\end{array}$} & $\begin{array}{l}\text { Primary } \\
\text { sexual } \\
\text { dysfunction }\end{array}$ & 10.4 & 5.0 & 5 & 25 \\
\hline & $\begin{array}{l}\text { Secondary } \\
\text { sexual } \\
\text { dysfunction }\end{array}$ & 18.7 & 7.1 & 9 & 41 \\
\hline & $\begin{array}{l}\text { Tertiary } \\
\text { sexual } \\
\text { dysfunction }\end{array}$ & 10.6 & 4.7 & 5 & 23 \\
\hline & MSISQ-19 & 39.7 & 15.3 & 19 & 83 \\
\hline \multirow[t]{5}{*}{ MSHQ } & Erection & 10.2 & 3.8 & 0 & 15 \\
\hline & Ejaculation & 26.7 & 7.3 & 1 & 35 \\
\hline & Satisfaction & 23.9 & 5.9 & 6 & 30 \\
\hline & $\begin{array}{l}\text { Sexual } \\
\text { activity }\end{array}$ & 9.8 & 2.2 & 3 & 15 \\
\hline & $\begin{array}{c}\text { Sexual urge } \\
\text { or desire }\end{array}$ & 14.6 & 3.1 & 4 & 20 \\
\hline \multirow[t]{5}{*}{ GHQ } & $\begin{array}{l}\text { Physical } \\
\text { symptoms }\end{array}$ & 7.4 & 4.0 & 0 & 21 \\
\hline & Anxiety & 7.7 & 5.0 & 0 & 21 \\
\hline & $\begin{array}{l}\text { Social } \\
\text { function }\end{array}$ & 7.3 & 3.8 & 0 & 21 \\
\hline & Depression & 4.0 & 4.4 & 0 & 20 \\
\hline & GHQ & 26.4 & 13.7 & 0 & 74 \\
\hline IIEF & & 48.0 & 11.34 & 5 & 75 \\
\hline SQOL-M & & 47.9 & 16.8 & 11 & 66 \\
\hline
\end{tabular}

MSISQ-19 Multiple Sclerosis Intimacy and Sexuality Questionnaire, $M S H Q$ Sexual Health Questionnaire, $G H Q$ General Health Questionnaire, IIEF International Index of Erectile Function, SQOL-M Sexual Quality of Life-Men

The results of backward multivariate logistic regression showed that the age, MSISQ-19, and SQOL-M were the strongest variables affecting
Table 3 Correlation coefficient matrix of MSISQ-19, MSHQ, GHQ, IIEF, and SQOL-M

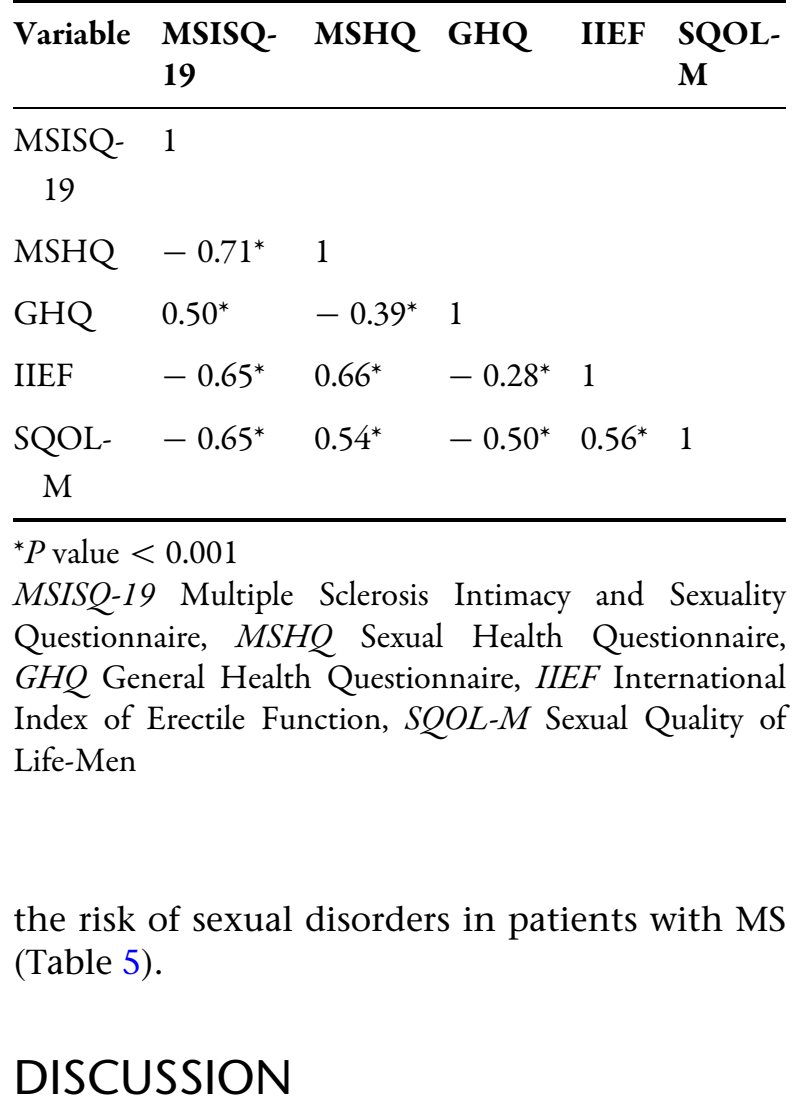

Sexual dysfunction in multiple sclerosis is almost five times more common than other neurological diseases [33]. People with MS, especially young people, consider SD to be the most negative feature of their disease with indirect effects on their mental health, quality of life, and intimate relationships [19].

In this study, the prevalence of SD in men with MS was estimated to be about $36 \%$, but the level of disability in the majority of participating patients $(77.2 \%)$ was low, and may mean the prevalence of SD must be higher in the total population of patients with MS, which might include a higher percentage of moderate and severe patients. Some studies have reported prevalence higher than this study. For example, a study from New South Wales, Australia showed that out of 283 people with MS, sexual difficulties were experienced in $74 \%$ of men and the most common sexual problems in men were respectively decreased frequency of sex, 
Table 4 Factors associated with sexual dysfunction (univariate logistic regression model)

\begin{tabular}{|c|c|c|c|c|c|c|}
\hline \multirow{2}{*}{$\begin{array}{l}\text { Characteristics } \\
\text { Age }\end{array}$} & $\begin{array}{l}\text { Without sexual dysfunction } \\
\text { Median }\left(Q_{1}-Q_{3}\right)\end{array}$ & \multicolumn{2}{|c|}{$\begin{array}{l}\text { With sexual dysfunction } \\
\text { Median }\left(Q_{1}-Q_{3}\right)\end{array}$} & Odds ratio & \multirow{2}{*}{$\begin{array}{l}95 \% \mathrm{CI} \\
1.02-1.08\end{array}$} & \multirow{2}{*}{$\begin{array}{l}P \text { value } \\
<0.001^{*}\end{array}$} \\
\hline & $35(30-43)$ & $40(34-46)$ & & 1.050 & & \\
\hline EDSS & $2(1-3)$ & $3(2-4)$ & & 1.45 & $1.24-1.70$ & $<0.001^{*}$ \\
\hline Duration of MS disease & $72(36-96)$ & $88(48-156)$ & & 1.005 & $1.002-1.009$ & $0.003^{*}$ \\
\hline MSISQ-19 & $31(22-39)$ & $52(43-58)$ & & 1.103 & $1.078-1.128$ & $<0.001^{*}$ \\
\hline GHQ & $22(14-28)$ & $30(25-39)$ & & 1.04 & $1.03-1.06$ & $<0.001^{*}$ \\
\hline \multirow[t]{2}{*}{ SQOL-M } & $60(47-66)$ & $34(25-47)$ & & 0.930 & $0.914-0.947$ & $<0.001^{*}$ \\
\hline & $N(\%)$ & $N(\%)$ & Odds ratio & $95 \%$ & CI & $P$ value \\
\hline \multicolumn{7}{|l|}{ Marital status } \\
\hline Single/separated/widowed & $42(20.4)$ & $19(16.7)$ & Ref & \multicolumn{2}{|l|}{-} & 0.418 \\
\hline Married & $164(79.6)$ & $95(83.3)$ & 1.280 & \multicolumn{2}{|c|}{$0.70-2.33$} & \\
\hline \multicolumn{7}{|l|}{ Children } \\
\hline None & $18(13.4)$ & $4(4.9)$ & Ref & \multicolumn{2}{|l|}{-} & 0.053 \\
\hline One or more & $116(86.6)$ & $78(95.1)$ & 3.026 & \multicolumn{2}{|c|}{$0.987-9.281$} & \\
\hline \multicolumn{7}{|l|}{ Education } \\
\hline High school or below & $84(40.8)$ & $52(45.6)$ & Ref & \multicolumn{2}{|l|}{-} & 0.402 \\
\hline University & $122(59.2)$ & $62(54.4)$ & 0.821 & \multicolumn{2}{|c|}{$0.517-1.302$} & \\
\hline \multicolumn{7}{|l|}{ Spouse education } \\
\hline High school or below & $70(42.7)$ & $43(45.3)$ & Ref & \multicolumn{2}{|l|}{-} & 0.687 \\
\hline University & $94(57.3)$ & $52(54.7)$ & 0.901 & \multicolumn{2}{|c|}{$0.541-1.498$} & \\
\hline \multicolumn{7}{|l|}{ Economic status } \\
\hline Excellent and good & $39(18.9)$ & $28(24.6)$ & 1.292 & \multicolumn{2}{|c|}{$0.668-2.499$} & 0.446 \\
\hline Moderate & $113(54.9)$ & $56(49.1)$ & 0.892 & \multicolumn{2}{|c|}{$0.515-1.545$} & 0.684 \\
\hline Weak & $54(26.2)$ & $30(26.3)$ & Ref & \multicolumn{2}{|l|}{-} & \\
\hline \multicolumn{7}{|l|}{ Exercise } \\
\hline No & $107(51.9)$ & $74(64.9)$ & Ref & \multicolumn{2}{|l|}{-} & $0.026^{*}$ \\
\hline Yes & $99(48.1)$ & $40(35.1)$ & 0.584 & \multicolumn{2}{|c|}{$0.364-0.936$} & \\
\hline \multicolumn{7}{|l|}{ Smoking } \\
\hline No & $157(76.2)$ & $71(62.3)$ & Ref & \multicolumn{2}{|l|}{ - } & $0.009^{*}$ \\
\hline Yes & $49(23.8)$ & $43(37.7)$ & 1.941 & 1.18 & -3.188 & \\
\hline Alcohol consumption & & & & & & \\
\hline No & $182(88.3)$ & $97(85.1)$ & Ref & - & & 0.404 \\
\hline Yes & $24(11.7)$ & $17(14.9)$ & 1.33 & 0.68 & -2.59 & \\
\hline
\end{tabular}


Table 4 continued

\begin{tabular}{|c|c|c|c|c|c|}
\hline & $N(\%)$ & $N(\%)$ & Odds ratio & $95 \% \mathrm{CI}$ & $P$ value \\
\hline \multicolumn{6}{|l|}{ Drug use } \\
\hline No & $188(91.3)$ & $102(89.5)$ & Ref & - & \multirow[t]{2}{*}{0.600} \\
\hline Yes & $18(8.7)$ & $12(10.5)$ & 1.23 & $0.57-2.65$ & \\
\hline \multicolumn{6}{|l|}{ Any psychiatric illness } \\
\hline No & $194(94.2)$ & $102(89.5)$ & Ref & - & \multirow[t]{2}{*}{0.131} \\
\hline Yes & $12(5.8)$ & $12(10.5)$ & 1.902 & $0.825-4.385$ & \\
\hline \multicolumn{6}{|l|}{ Non-MS chronic disease } \\
\hline No & $118(57.3)$ & $47(41.2)$ & Ref & - & \multirow[t]{2}{*}{$0.006^{*}$} \\
\hline Yes & $88(42.7)$ & $67(58.8)$ & 1.91 & $1.20-3.04$ & \\
\hline \multicolumn{6}{|l|}{ Type of MS } \\
\hline RRMS & $123(59.7)$ & $65(57.0)$ & 0.752 & $0.419-1.350$ & 0.339 \\
\hline PRMS & $36(17.5)$ & $19(16.7)$ & 0.751 & $0.355-1.588$ & 0.454 \\
\hline PPMS & $10(4.9)$ & $4(3.5)$ & 0.569 & $0.161-2.014$ & 0.382 \\
\hline SPMS & $37(18.0)$ & $26(22.8)$ & Ref & - & \\
\hline \multicolumn{6}{|l|}{ Regular sexual activity } \\
\hline No & $83(40.3)$ & $84(73.7)$ & Ref & - & \multirow[t]{2}{*}{$<0.001^{*}$} \\
\hline Yes & $123(59.7)$ & $30(26.3)$ & 0.241 & $0.15-0.40$ & \\
\hline \multicolumn{6}{|l|}{ Main sexual partner } \\
\hline No & $51(24.8)$ & $13(11.4)$ & Ref & - & \multirow[t]{2}{*}{$0.005^{*}$} \\
\hline Yes & $155(75.2)$ & $101(88.6)$ & 2.56 & $1.32-4.94$ & \\
\hline \multicolumn{6}{|l|}{ Type of medicine } \\
\hline High efficacy & $103(50.0)$ & $47(41.2)$ & Ref & - & \multirow[t]{2}{*}{0.133} \\
\hline Low to moderate efficacy & $103(50.0)$ & $67(58.8)$ & 1.43 & $0.90-2.26$ & \\
\hline
\end{tabular}

Values presented as no. (\%), unless otherwise stated

${ }^{*} P$ values is significant

$Q_{1}$ quartile $1, Q_{3}$ quartile 3, MSISQ-19 Multiple Sclerosis Intimacy and Sexuality Questionnaire, MSHQ Sexual Health Questionnaire, GHQ General Health Questionnaire, IIEF International Index of Erectile Function, SQOL-M Sexual Quality of Life-Men, RRMS relapsing-remitting multiple sclerosis, SPMS secondary progressive multiple sclerosis, PPMS primary progressive multiple sclerosis, RPMS relapsing-progressive multiple sclerosis, EDSS Expanded Disability Status Scale

dissatisfaction with sexual function, masturbation problems, difficulty in achieving orgasm, erectile dysfunction, and delayed or premature ejaculation [11]. The prevalence of SD in men with MS in Italy was 92.1\% [33], in Belgrade, Serbia it was 84\% [10], in Derbyshire, England it was 76\% [34], and in Hordaland, Norway it was $50 \%$ [12], which are higher that this current 
Table 5 Factors associated with sexual dysfunction (backward multivariate logistic regression)

\begin{tabular}{lllr}
\hline Characteristics & Odds ratio & \multicolumn{1}{l}{ 95\% CI } & $\boldsymbol{P}$ value \\
\hline Age & 1.037 & $1.006-1.070$ & 0.021 \\
MSISQ-19 & 1.068 & $1.041-1.096$ & $<0.001$ \\
SQOL-M & 0.955 & $0.935-0.975$ & $<0.001$ \\
\hline
\end{tabular}

study. But in Brazil it was lower than our study (31.1\%) [18]. A cohort study in Argentina stated that SD was very common in patients with MS, and erectile dysfunction affected $89 \%$ of men with MS, compared to $26 \%$ in healthy volunteers. Also, these patients had experienced more intense orgasms (52\%), longer time to reach orgasm (48\%), and decreased libido (22\%) [35]. Erectile dysfunction was also reported in two other studies in Croatia as the most prominent symptom of $\mathrm{SD}$, with a relatively similar occurrence [36, 37].

It seems that one reason for the lower prevalence of SD in men with MS in Iran, compared to other world studies, is that Iranian men think SD is a disgrace, and may not feel comfortable to declare that they have SD and therefore may have not stated their real situation in the questionnaires. Studies from Australia showed that only about half of men (55\%) with MS had talked about their sexual problems, and from those only $29 \%$ had been able to access help to solve their sexual problems [11].

The results of our study are consistent with other studies on the relation between SD and sexual quality of life in men with MS. For example, Balsamo et al. [23] studied 101 male patients with MS in Italy, and showed that the sexual quality of life in men (based on the SQOL-M questionnaire) was significantly associated with erectile dysfunction, and the mean Sexual Quality of Life Questionnaire-Male score in patients with MS with and without erectile dysfunction was $29.3 \pm 16.6$ and $73.1 \pm 21.5$, respectively. In Tepavcevic's study in Serbia, the analysis of various sexual problems (especially decreased libido, premature ejaculation, and erection loss) in 109 patients with MS showed a significant reduction in sexual function scores and satisfaction in MS men, and overall, the frequent incidence of SD in patients with MS significantly affected all aspects of their quality of life [10]. In Hordland, Norway, researchers also reported an increase in the prevalence of sexual problems, along with a decrease in quality of life, with men having a major problem with achieving or maintaining erection [12].

According to the results of the present study, exercise and physical activity were inversely related with SD in patients with MS. Some results suggest that increased physical activity improves SD symptoms, and this may be due to its positive effects on mood [38, 39]. Also a cohort study [19] showed that having a high level of physical activity was associated with a higher chance of satisfactory sexual function. The results of the aforementioned three studies are consistent with the results of the present study.

The present study also showed that sexual activity was inversely related to SD in patients with MS. Apparently, these two variables are related to each other, bidirectionally. Not having regular sexual activity can cause $\mathrm{SD}$, and SD can lead to decreased sexual activity. But in contrast, the results of Zivadinov's study in Italy showed no significant relation between SD and the number or frequency of sexual intercourse [37].

On the other hand, some factors showed positive associations with SD. The results of our study showed that depression was directly associated with an increased chance of SD. Depression is the most common psychiatric disorder in patients with MS and is more common in MS than other chronic diseases [40]. A systematic review on articles up to 2011 also showed the bidirectional relation between depression and SD [41]. A recent prospective study in Croatia also found that depressed patients with MS showed SD symptoms significantly more and their sexual quality of life was less than non-depressed patients [36]. In a cohort study of 2062 patients with multiple sclerosis in 54 countries, the total mean of the sexual function score was 75.0 out of 100 , and only $43.7 \%$ were satisfied with their sexual function; and SD and dissatisfaction of sexual 
function were associated with the risk of depression [19], which is consistent with the results of the present study. In another research, Balsamo et al. [23] found a significant inverse relation between depression symptoms with erectile function (EF) and sexual quality of life in MS men, which was in line with our results. Similarly, the result of Zavoreo's study in Croatia, 2016, shows a direct relation between depression and SD, which indicates decreased quality of life in such patients. In that study, the incidences of depression and SD in patients with MS were $57 \%$ and $71 \%$, respectively [42]. However, two studies in the UK reported different results, and suggest no link between sexual function and depression in patients with MS [43, 44].

In terms of other risk factors in the present study, we found a significant association between SD and having a main sexual partner, so that people with a main sexual partner were more likely to have reported SD. This is probably because someone who does not have a main partner may have low expectations for his sexual activity, so they are less likely to notice or report SD. But men who have a main partner notice a decrease in their sexual function more than others and are more likely to report it.

The results of our study also showed that age, MS duration, EDSS, non-MS chronic diseases, and having a main sexual partner were significantly associated with the prevalence of SD. In this regard, some previous studies have reported a positive and significant relation between SD and age, MS duration, degree of disability, having chronic diseases, drug use, and low level of education [10, 11, 19, 33, 37], but another study did not show any correlation between SD and the duration of disease [37]. In the present study, although age, duration of disease, MSISQ-19, and GHQ were significantly higher, and SQOL-M was significantly lower in patients with SD, the odds ratios were trivial, except for EDSS.

The mean age of patients in this current study was 38.4 years and $59.7 \%$ of patients were in the 17-39 years age range, confirming that MS is a disease of young adults [45]. In some studies, the mean age of patients was between
30 and 40 years [10, 42, 46, 47], and in others it was between 40 and 45 years [23, 48].

In the present study, the mean duration of MS disease was $88.1 \pm 67.6$ months. In other studies $[10,42,47,48]$, the duration of the disease was reported to be between 5 and 9 years, which is more or less consistent with the present study. According to reports, the first signs of the disease will typically appear before the age of 30 years; therefore, the disease appears mainly in young people and the duration of the disease is usually short.

The results of the present study showed that more than half of patients $(57.5 \%)$ had a university degree and $52.8 \%$ had an average economic level. In other studies, the majority of patients were people with university education [42, 48, 49] and in Kuwait, $63.8 \%$ of patients with MS had high income [50]. According to the latest census of the Statistics Organization of Iran in 2016, most people in the age group of 20-29 years have a university degree [51]. Usually educated people have a higher chance of finding well-paid jobs, and therefore have a better socioeconomic status.

\section{Strengths and Limitations}

Since the subject of SD in men with MS in Iran has not been studied so far, this study is the first study about this topic in Iran, and the results of this study can be used to understand the situation and compare with similar studies in other countries that have a culturally different view about expressing sexual problems.

This study also had limitations. All of our study data were self-reported, and could not be fully validated. Also we did not evaluate the presence of depression through a specific depression scale, and it was determined by the GHQ, which was easier to apply. Meanwhile, this was a cross-sectional study and can only show associations and not causation.

Also, we determined the sample size assuming the prevalence of SD to be $70 \%$. However, the sample size with the prevalence determined in our study $(35.6 \%)$ was 352 , which is very close to the previously determined sample size, 
and means that the study was probably not underpowered.

\section{CONCLUSIONS}

The prevalence of SD in men with MS in Iran is relatively high. Important factors such as age, duration of MS, and exercise are related to the prevalence of SD in men with MS. It is necessary to inform patients that SD is a common problem in MS and they should talk to their doctor about their sexual concerns and seek professional help to improve their sexual function. Also, since physical, psychological, and neurological factors have negative effects on sexual function, patients with MS should also be screened, diagnosed, and treated for these factors.

\section{ACKNOWLEDGEMENTS}

The authors thank all patients for their kind participation in this project.

Funding. This study was funded and supported by Ahvaz Jundishapur University of Medical Sciences, Grant No. SDH-9924. No Rapid Service Fee was received by the journal for the publication of this article.

Authorship. All named authors meet the International Committee of Medical Journal Editors (ICMJE) criteria for authorship for this article, take responsibility for the integrity of the work as a whole, and have given their approval for this version to be published.

Authors' Contributions. SMN and HR conceived and designed the project. SMN, NM, ZS, MZ, SK, AEE, FA, RA, MJ, GG and RG acquired the data. MD analyzed the data. MD, NK (fourth author) and NK (fifth author) wrote the paper. All authors approved the final text.

Disclosures. All authors (Seyed Massood Nabavi, Maryam Dastoorpoor, Nastaran Majdinasab, Narges Khodadadi, Narges Khanjani, Zohreh Sekhavatpour, Maryam Zamanian,
Sasan Kazemian, Amir Ebrahim Eftekhari, Fereshteh Ashtari, Roya Abolfazli, Mahdi Jalili, Gholamhossein Ghaedi and Hamid Reza Ghalianchi) declare that they have no competing interests.

Compliance with Ethics Guidelines. Ethics approval was obtained from the ethics committee of Ahvaz Jundishapur University of Medical Sciences (IR.AJUMS.REC.1399.556). According to the ethics in research regulations in Iran, ethics committee approval was not needed to be obtained from each study site, separately, and the research could proceed with ethics approval from just one Iranian university. Necessary permits to conduct this research were obtained. This study was performed in accordance with the Helsinki 1964 Declaration. Oral informed consent was inquired from the patients that participated in this study. Patients were assured that their information would remain confidential.

Data Availability. The datasets generated during and/or analyzed during the current study are available from the corresponding author on reasonable request.

Open Access. This article is licensed under a Creative Commons Attribution-NonCommercial 4.0 International License, which permits any non-commercial use, sharing, adaptation, distribution and reproduction in any medium or format, as long as you give appropriate credit to the original author(s) and the source, provide a link to the Creative Commons licence, and indicate if changes were made. The images or other third party material in this article are included in the article's Creative Commons licence, unless indicated otherwise in a credit line to the material. If material is not included in the article's Creative Commons licence and your intended use is not permitted by statutory regulation or exceeds the permitted use, you will need to obtain permission directly from the copyright holder. To view a copy of this licence, visit http://creativecommons.org/licenses/by$\mathrm{nc} / 4.0 /$. 


\section{REFERENCES}

1. Mousavizadeh A, Dastoorpoor M, Naimi E, Dohrabpour K. Time-trend analysis and developing a forecasting model for the prevalence of multiple sclerosis in Kohgiluyeh and Boyer-Ahmad Province, Southwest of Iran. Public Health. 2018;154:14-23.

2. Browne P, Chandraratna D, Angood C, et al. Atlas of multiple sclerosis 2013: a growing global problem with widespread inequity. Neurology. 2014;83(11): 1022-4.

3. Heydarpour P, Mohammad K, Yekaninejad MS, Elhami S-R, Khoshkish S, Sahraian MA. Multiple sclerosis in Tehran, Iran: a joinpoint trend analysis. Mult Scler J. 2014;20(4):512.

4. Elhami S-R, Mohammad K, Sahraian MA, Eftekhar H. A 20-year incidence trend (1989-2008) and point prevalence (March 20, 2009) of multiple sclerosis in Tehran, Iran: a population-based study. Neuroepidemiology. 2011;36(3):141-7.

5. McFarlin DE, McFarland HF. Multiple sclerosis. N Engl J Med. 1982;307(20):1246-51.

6. Shafa MA, Khanjani N. A study of the seasonal incidence of multiple sclerosis attacks in Kerman, Iran. J Kerman Univ Med Sci. 2014;21(5):376-83.

7. World Health Organization. International statistical classification of diseases and related health problems: Tabular list. World Health Organization; 2004.

8. Pöttgen J, Rose A, van de Vis W, et al. Sexual dysfunctions in MS in relation to neuropsychiatric aspects and its psychological treatment: a scoping review. PLoS ONE. 2018;13(2):e0193381.

9. Lew-Starowicz M, Rola R. Prevalence of sexual dysfunctions among women with multiple sclerosis. Sex Disabil. 2013;31(2):141-53.

10. Tepavcevic D, Kostic J, Basuroski I, Stojsavljevic N, Pekmezovic T, Drulovic J. The impact of sexual dysfunction on the quality of life measured by MSQoL-54 in patients with multiple sclerosis. Mult Scler J. 2008;14(8):1131-6.

11. Redelman MJ. Sexual difficulties for persons with multiple sclerosis in New South Wales, Australia. Int J Rehabil Res. 2009;32(4):337-47.

12. Nortvedt M, Riise T, Frugaård J, et al. Prevalence of bladder, bowel and sexual problems among multiple sclerosis patients two to five years after diagnosis. Mult Scler J. 2007;13(1):106-12.
13. Kingsberg S. Loss of sexual desire and menopause: prevalence causes and impact on quality of life. Female Patient. 2005;30:57-63.

14. Beits C, Jones S, Fowler C, Fowler CJ. Erectile dysfunction in multiple sclerosis associated neurological and neurophysiological deficits, and treatment of the condition. Brain. 1994;117(6):1303-10.

15. Sanders AS, Foley FW, LaRocca NG, Zemon V. The multiple sclerosis intimacy and sexuality questionnaire-19 (MSISQ-19). Sex Disabil. 2000;18(1):3-26.

16. Schmidt E, Hofmann P, Niederwieser G, Kapfhammer H-P, Bonelli R. Sexuality in multiple sclerosis. J Neural Transm. 2005;112(9):1201-11.

17. Zephir H, De Seze J, Stojkovic T, et al. Multiple sclerosis and depression: influence of interferon B therapy. Mult Scler J. 2003;9(3):284-8.

18. Finkelsztejn A, Cristovam RDA, Moraes GSD, et al. Clinical features of multiple sclerosis in the south of Brazil: a partial analysis. Arq Neuropsiquiatr. 2009;67(4):1071-5.

19. Marck CH, Jelinek PL, Weiland TJ, et al. Sexual function in multiple sclerosis and associations with demographic, disease and lifestyle characteristics: an international cross-sectional study. BMC Neurol. 2016;16(1):210.

20. DeLamater J, Karraker A. Sexual functioning in older adults. Curr Psychiatry Rep. 2009;11(1):6-11.

21. Ghadiri M, Foroutan S. Sexual dysfunctions, the hidden cause of divorce: the necessity of the presence of a trained physician as a member of family counseling centers. J Fam Res. 2009;4:585-608.

22. Nezhad MZ, Goodarzi AM. Sexuality, intimacy, and marital satisfaction in Iranian first-time parents. J Sex Marital Ther. 2011;37(2):77-88.

23. Balsamo R, Arcaniolo D, Stizzo M, et al. Increased risk of erectile dysfunction in men with multiple sclerosis: an Italian cross-sectional study. Central Eur J Urol. 2017;70(3):289.

24. Previnaire J, Lecourt G, Soler J, Denys P. Sexual disorders in men with multiple sclerosis: evaluation and management. Ann Phys Rehabil Med. 2014;57(5):329-36.

25. Rosen RC, Catania J, Pollack L, Althof S, O'Leary M, Seftel AD. Male Sexual Health Questionnaire (MSHQ): scale development and psychometric validation. Urology. 2004;64(4):777-82.

26. Fakhri A, Morshedi H, Soleymanian A, Hosaini M. Psychometric properties of Iranian version of Male 
Sexual Function Index. Jundishapur Sci Med J. 2014;12:6.

27. Rosen RC, Riley A, Wagner G, Osterloh IH, Kirkpatrick J, Mishra A. The international index of erectile function (IIEF): a multidimensional scale for assessment of erectile dysfunction. Urology. 1997;49(6):822-30.

28. Mohammadi K, Rahnama P, Tabar SM, Montazeri A. Validation of the persian version of multiple sclerosis intimacy and sexuality questionnaire-19 (MSISQ-19). Payesh (Health Monitor). 2014;13(5): 601-7.

29. Abraham L, Symonds T, Morris MF. Psychometric validation of a sexual quality of life questionnaire for use in men with premature ejaculation or erectile dysfunction. J Sex Med. 2008;5(3):595-601.

30. Sadat Z, Ghofranipour F, Goshtasebi A, Azin SA. Validity and relibility of the Persian version of the Sexual Quality of Life-Male questionnaire. Payesh (Health Monitor). 2017;16(1):73-80.

31. Goldberg DP, Hillier VF. A scaled version of the General Health Questionnaire. Psychol Med. 1979;9(1):139-45.

32. Nourbala A, Bagheri YS, MOHAMMAD K. The validation of general health questionnaire- 28 as a psychiatricscreening tool. Hakim Res J. 2009;11(4): 47-53.

33. Zorzon M, Zivadinov R, Bosco A, et al. Sexual dysfunction in multiple sderosis: a case-control study. 1. Frequency and comparison of groups. Mult Scler J. 1999;5(6):418-27.

34. Vazirinejad R, Lilley J, Ward C. A health profile of adults with multiple sclerosis living in the community. Mult Scler J. 2008;14(8):1099-105.

35. Contentti EC, Pettinicchi JP, Caride A, López PA. Sexual dysfunction in patients with multiple sclerosis from Argentina: what are the differences between women and men? Sex Disabil. 2019;37(4): 521-39.

36. Pašiü $H$, Vujeviü $L$, Pašiü $M B$, et al. Sexual dysfunction and depression in patients with multiple sclerosis in Croatia. Psychiatr Danub. 2019;31(5): S831-8.

37. Zivadinov R, Zorzon M, Bosco A, et al. Sexual dysfunction in multiple sderosis: II. Correlation analysis. Mult Scler J. 1999;5(6):428-31.

38. Derby CA, Mohr BA, Goldstein I, Feldman HA, Johannes CB, McKinlay JB. Modifiable risk factors and erectile dysfunction: can lifestyle changes modify risk? Urology. 2000;56(2):302-6.
39. Lewis RW, Fugl-Meyer KS, Bosch R, et al. Epidemiology/risk factors of sexual dysfunction. J Sex Med. 2004;1(1):35-9.

40. Feinstein A, Feinstein K. Depression associated with multiple sclerosis: looking beyond diagnosis to symptom expression. J Affect Disord. 2001;66(2-3): 193-8.

41. Atlantis E, Sullivan T. Bidirectional association between depression and sexual dysfunction: a systematic review and meta-analysis. J Sex Med. 2012;9(6):1497-507.

42. Zavoreo I, Gržinčić T, Preksavec M, Madžar T, Bašić Kes V. Sexual dysfunction and incidence of depression in multiple sclerosis patients. Acta Clin Croatica. 2016;55(3):402-6.

43. Young CA, Tennant A, Group TS. Sexual functioning in multiple sclerosis: relationships with depression, fatigue and physical function. Mult Scler J. 2017;23(9):1268-75.

44. Dupont S. Sexual function and ways of coping in patients with multiple sclerosis and their partners. Sex Marital Therapy. 1996;11(4):359-72.

45. Milo R, Kahana E. Multiple sclerosis: geoepidemiology, genetics and the environment. Autoimmun Rev. 2010;9(5):A387-94.

46. Marrie RA, Horwitz R, Cutter G, Tyry T, Vollmer T. Association between comorbidity and clinical characteristics of MS. Acta Neurol Scand. 2011;124(2):135-41.

47. Odabaş FÖ, Gümüş H, Akkurt HE, Uca AU, Yilmaz $H$. The assessment of sexual dysfunction in male patients with multiple sclerosis. Arch Neuropsychiatry. 2018;55(4):349.

48. Marck CH, Jelinek PL, Weiland TJ, et al. Sexual function in multiple sclerosis and associations with demographic, disease and lifestyle characteristics: an international cross-sectional study. BMC Neurol. 2016;16(1):1-9.

49. Taylor KL, Hadgkiss EJ, Jelinek GA, et al. Lifestyle factors, demographics and medications associated with depression risk in an international sample of people with multiple sclerosis. BMC Psychiatry. 2014;14(1):1-12.

50. El-Muzaini H, Akhtar S, Alroughani R. A matched case-control study of risk factors associated with multiple sclerosis in Kuwait. BMC Neurol. 2020;20(1):1-7.

51. Census-group. Assessing the literacy status and education of the population aged 6 and over based on general population and housing censuses 
1986-2016. Publications of Statistics Center of Iran. 2019. https://www.amar.org.ir/\%D8\%AE\%D8\%A7\% D9\%86\%D9\%87/\%D8\%A2\%D8\%B1\%D8\%B4\%DB \%8C\%D9\%88-\%D8\%AA\%D8\%A7\%D8\%B2\%D9\%
87\%D9\%87\%D8\%A7\%DB\%8C-\%D9\%86\%D8\%B4 \%D8\%B1/agentType/View/PropertyID/10938. Accessed 08 May 2009. 